the comprehension of migrant cleaners at work. - European Journal of Applied Linguistics 4 s. 239-275. https://doi. org/10.1515/eujal-2015-0039.

- 2017: Work-related language learning trajectories of migrant cleaners in
Finland. - Apples. Journal of Applied

Language Studies 11 (4) s. 137-16o.

https://doi.org/10.17011/apples/

urn.201712214863.

Wertsch, James 1998: Mind as action.

Oxford: Oxford University Press.

\title{
Mikael Agricolan yhteen kirjoittamien yhdyssanojen rakenteen kuvausta
}

Tanja Toropainen: Yhdyssanat ja yhdyssanamaiset rakenteet Mikael Agricolan teoksissa. Turun yliopiston julkaisuja C 439. Turku: Turun yliopisto 2017. Johdanto 85 s. (+ liitteet 37 s.) ja viisi artikkelia 120 s. ISBN 978-951-29-6874-9.

Tanja Toropainen tarkastelee artikkeliväitöskirjassaan Mikael Agricolan yhdyssanoja tavoitteenaan kuvata Agricolan käyttämät yhdyssanojen rakennetyypit, selvittää yhdyssanarakenteiden alkuperää ja vakiintumista sekä arvioida yhdyssanan käsitettä vanhan kirjakielen aineiston pohjalta.

Väitöskirja koostuu viidestä artikkelista (Vaittinen 2003, 2007; Toropainen 2014, 2015, 2016) ja yhteenvedosta. Artikkeleista yksi on ilmestynyt Virittäjässä, muut on julkaistu Sananjalassa. Artikkeleissa käsitellään 1) yhdysverbejä, 2) yhdysadjektiiveja, 3) ylen-alkuisia yhdyssanoja, jotka voivat olla verbejä, substantiiveja, adjektiiveja tai adverbeja, 4) adjektiivialkuisia, kongruoivia yhdyssubstantiiveja ja 5) typografian vaikutusta yhdyssubstantiivien yhteen kirjoittamiseen Agricolan teoksissa. Väitöskirjan laajassa yhteenvedossa on täydennetty artikkeleista syntyvää kuvaa ja esitelty Agricolan yhdyssanojen rakennetyypit sanaluokittain käyttämällä koko pitkän prosessin aikana kertynyttä aineistoa. Yhteenvedossa esitetty kuvaus on täydentynyt erityisesti yhdyssubstantiivien osalta. Yhteenveto on huomattavan pitkä, ilman liitteitä 85 sivua, mikä ylittää selvästi sille asetetun suosituspituuden (Turun yliopistossa 50 s.). Kolme liitettä (yht. 37 s.) esittelevät väitöskirjaaineiston kokonaisuudessaan.

\section{Mikä on yhdyssana?}

Nykyisin suomen kirjakielessä yhdyssanan tunnistaa siitä, että sen osat on kirjoitettu yhteen (ks. esim. Koivisto 2013: 329). Yhdyssanojen yhteen ja erilleen kirjoittamisen vakiintuminen nykyisenkaltaiseksi on kuitenkin vaatinut pitkän ajan. Kuten väitöskirjan yhteenvedossakin todetaan (s. 24-25), vanhimmissa suomen kieliopeissa yhteen kirjoittamista ei vielä pidetty yhdyssanojen tuntomerkkinä. Kirjasuomen ensimmäisinä vuosisatoina ortografia oli monin tavoin horjuvaa; yhdyssanojen osalta se tarkoitti yhteen ja erikseen kirjoittamisen vakiintumattomuutta. Toropaisen tutkimusasetelma on haastava, koska voidaan kysyä, onko Agricolan yhdyssanoja tai muita varhaisia 
yhdyssanoja edes mahdollista perusteellisesti kuvata juuri siksi, että kattavan aineiston luotettava kerääminen on työlästä ja vaikeaa.

Käsitteiden sana, yhdyssana, sanaliitto ja lekseemi määrittely yhteenvedon luvussa 3 nostaa esiin kiinnostavia kysymyksiä, vaikka itsenäistä teoreettista näkemystä siinä ei esitetäkään vaan nojaudutaan pääosin lähteisiin. Lekseemille esitetty määritelmä sai minut kuitenkin pohtimaan, eikö myös sanaliittoja ole pidettävä lekseemeinä. Esimerkiksi erikoisalasanastoissa yhdyssana- ja sanaliittotermit ovat täysin rinnasteisia itsenäisten käsitteiden nimityksiä. Itse asiassa terminologiaopin alalla suomeksi sanaliittotermiksi nimitetty termityyppi on englanniksi compound term, josta yhdyssanatermi eroaa vain ortografisesti (complex term) (Tieteen termipankki 8.11.2017: Terminologiaoppi: sanaliittotermi, Terminologiaoppi:yhdyssanatermi).

Määritellessään sanaa (s. 27) Toropainen esittää lähteisiin nojaten, että yhdyssanaa voi pitää sanana, koska sanajärjestystä vaihdettaessa se siirtyy aina kokonaisuutena. Tämä on tietysti totta (paitsi aineiston yhdysverbien yhteydessä), mutta kyseinen osien yhdessä pysymisen kriteeri ei erota yhdyssanaa sanaliitoista, jotka myös siirtyvät kokonaisuutena. Ovatko siis myös sanaliitot sanoja?

Esitellessään yhdyssanan määritelmiä Toropainen ei kerro selvästi nojautuvansa mihinkään aiemmista kuvauksista, vaan hänen käyttämänsä käsitys yhdyssanasta paljastuu itse tutkimuksesta ja oikeastaan jo yhteenvedon nimestä: "Yhdyssanat ja yhdyssanamaiset rakenteet". Yhteenvedossa "yhdyssanamaisen rakenteen" paljastetaan tarkoittavan "sellaisia sanaliittoja, jotka muotonsa ja merkityksensä puolesta muistuttavat yhdyssanoja" (esim. s. 5), vaikka aivan hyvin niitäkin voisi nimittää yhdyssanoiksi. Yhdyssanalla tarkoitetaan siis nykykäsityksen mukaisesti vain yhteen kirjoitettuja yhdyssanoja, yhdyssana- maisilla rakenteilla erikseen kirjoitettuja. Toisin sanoen Toropaisen yhdyssana määräytyy ortografian perusteella.

Vaikka yhteenvedossa (esim. s. 45-46) nostetaan esiin nykykielen yhdyssanakäsityksestä irtautumisen tärkeys tällaisessa tutkimuksessa, isoissa ratkaisuissa, kuten aineistonkeruussa, nykykielen käsityksestä ja ortografiavetoisuudesta ei ole pystytty irtautumaan. Väitöskirjaa täytyy siis pitää ennen kaikkea Agricolan teoksissa esiintyvien yhteen kirjoitettujen sanayhtymien, ei kaikkien Agricolan yhdyssanojen, tarkasteluna.

\section{Aineisto ja menetelmät}

Aineisto on saatu pääosin Agricolan teoksista laadituista toimitetuista aineistoista, joko Kotimaisten kielten keskuksen Vanhan kirjasuomen sanakirjan aineskokoelman sanalippujen kopioista tai korpushauilla Kotuksen Kaino-korpuksesta tai Turun yliopistossa laaditusta Agricolan morfosyntaktisesta tietokannasta. Viimeiseen artikkeliin aineistoa on kerätty myös näköispainoksista käsin poimimalla.

Aineistoon on poimittu systemaattisesti Agricolan yhteen kirjoittamat yhdyssanat, mutta erikseen kirjoitetut yhdyssanat, joiden mukaanotto olisi vaatinut semanttista tarkastelua, ovat jääneet pääosin aineiston ulkopuolelle. Näin aineistossa ei esimerkiksi ole erikseen kirjoitettuja adjektiivialkuisia yhdyssubstantiiveja, genetiivialkuisia substantiiviyhtymiä eikä verbiyhtymiäkään, elleivät vastaavat esiinny myös yhteen kirjoitettuina. Ilahduttava poikkeus on viimeinen artikkeli (ks. Toropainen 2016), jonka aineistossa ovat mukana myös erikseen kirjoitetut, niin sanotut luontaiset yhdyssanat eli substantiivin nominatiivimuodolla, yhdysosamuodolla tai nominivartalolla alkavat yhdyssubstantiivit.

Toropaisen tutkimusmenetelmä on aineistopohjainen ja vertaileva. Aineisto on karttunut 13 vuoden aikana artikkeleina 
julkaistujen tutkimusten ohessa. Tällä tavalla on syntynyt väitöskirjan yhteenvedossa esitelty yhdyssanatietokanta, johon on koottu yhteensä 24195 yhdyssanaesiintymää, jotka sisältävät yhteensä 2493 eri lekseemiä (asetelma 1, s. 38). Erillisiksi lekseemeiksi on laskettu myös hieman eri tavoin kirjoitetut saman yhdyssanan esiintymät (esim. hyvähajullinen, hyvänhajullinen; jälkeentulevainen, jälkiintulevainen). Tätä ratkaisua perustellaan viittaamalla Päivi Laineen (2007) väitöskirjaan, jossa kaikki eri tavoin kirjoitetut sananmuodot on laskettu eri lekseemeiksi. Laine kuitenkin tarkasteli myös ortografian vakiintumista $1800-l u v u l l a$, ja hän olisi todennäköisesti laskenut aineistoonsa erillisinä myös yhteen ja erilleen kirjoitetut vastaavat tapaukset, jos niitä olisi 1800 -luvulla ollut.

Jokaista osatutkimusta varten on kerätty erillinen aineisto. Aineistonkeruun huolellisuudesta voi vakuuttua, kun jokaisessa artikkelissa käytetään runsaasti tilaa sellaistenkin aineistosta löytyneiden rajatapausten käsittelyyn, jotka on päätetty jättää pois tarkastelusta. Tarkka menetelmien selostus tietysti lisää luotettavuutta, mutta liiallisesta yksityiskohtaisuudesta luettavuus kärsii.

Väitöskirja on yhtenäinen kokonaisuus, vaikka pitkä ajanjakso ensimmäisen ja viimeisen osatutkimuksen välillä näkyy niin tavoitteiden, menetelmien kuin tulosten esittämisen moninaisuudessa. Esimerkiksi ensimmäisissä artikkeleissa sanaesimerkit on normaalistettu nykykielisiksi, kun myöhemmissä artikkeleissa on esitetty sekä sanan aito ortografinen asu että nykyiseen kirjoitusjärjestelmään muokattu vastine. Vanhimmissa artikkeleissa käytetty ratkaisu vaikeuttaa arviointia: lukija ei voi olla varma, mistä lähtökohdasta sanat on nykykielistetty tai onko tekijä nykykielistänyt esimerkit oikein. Tämä koskee myös yhteenvedon liitettä 1. Lisäksi Agricolan teoksista käytetyt nimitykset vaihtelevat eri artikkeleissa. Yhdyssanarakentei- den alkuperän ja vakiintumisen selvittäminen on tavoitteena vain osassa artikkeleista.

Tekijä suhtautuu asianmukaisen kriittisesti käyttämiinsä toimitettuihin aineistoihin (esim. s. 40). Hän toteaa esimerkiksi, että Vanhan kirjasuomen sanakirjan aineskokoelmaan on sanastettu liian vähän kirjallisia käännöslainoja ja että yhdysverbien sanastaminen on ollut epäsystemaattista. Myös ihan tavallinen yhä käytössä oleva sanasto on usein jäänyt sanastamatta. Yhdyssanatutkijaa luonnollisesti on haitannut myös se, että mukana on vain sellaisia yhdyssanoja, jotka on tunnistettu yhdyssanoiksi nykykielen perusteella. Todetuista puutteista huolimatta väitöskirjassa on käytetty monissa laskelmissa pohjana Raimo Jussilan (1988) arvioita, jotka perustuvat Vanhan kirjasuomen sanakirjan ensimmäisestä osasta tehtyihin laskelmiin. Esimerkiksi yhteenvedossa (s. 74) esitetty arvio, jonka mukaan Agricolan yhdyssanoista on säilynyt nykykieleen vain $15,9 \%$, on todennäköisesti virheellinen.

\section{Tulosten tarkastelua}

Väitöskirja tuo runsaasti uutta, yksityiskohtaista tietoa Agricolan yhteen kirjoitettujen yhdyssanojen rakennetyypeistä. Tutkimuksen keskeisintä antia onkin yhdyssubstantiiveista, -adjektiiveista ja -verbeistä esitetty analyysi. Yhteen kirjoitettujen pronominien ja adverbien tarkastelu yhdyssanoina (esim. eikenenkään, eimitään, itsesinus, siihenasti, senedestä, juuriniin) on osoitus siitä, että aineistonkeruussa yhteen kirjoittaminen on ollut keskeinen peruste yhdyssanoiksi laskemiselle.

Esimerkiksi Agricolan yhdyssubstantiivien alkuosa on tavallisimmin nominatiivissa (ehtoosade, hakomaja), mutta myös genetiivi on yleinen (aamunkaste, kylänlapsi; kamelienvarsa, tekoinopettaja). Lisäksi käytössä on myös translatiivi-, illatiivi- ja instruktiivimuotoisia alkuosia 
(lihaksisikiäminen, huoneeseenottaminen, kielinkantaja). Alkuosana voi olla myös taipumattomia ja vajaaparadigmaisia sanavartaloita ja yhdysosamuotoja (epätieto, esimerkki, lähinaapuri, elinaika, tuulispää). Erikoinen rakennetyyppi on possessiivisuffiksin sisältävä alkuosa (ympärinsleikkaus). (S. 58-59.)

Yhdysadjektiivien yleisimmässä tyypissä jälkiosana on inen-johdos (erinomainen, jokapäiväinen), mutta jälkiosina esiintyvät myös marginaalisemmat johdostyypit (heikkouskolinen, epäkelvoton, suurivaltias), partisiipit (edelveisattapa, jumalanpelkäävä), superlatiivimuodot (kaikkeinrakkain) ja johtamattomat perussanat (kostonahne). (S. 60-61.)

Yhdysverbeistä yleisimpänä tyyppinä yhteenvedossa esitetään sellaiset, joiden alkuosana on tulosijassa, olosijassa tai erosijassa oleva adverbi (alasastua, lähestulla, vastaanseisoa; edelläkäydä, edessäpitää; päältäkatsoa). Yhdysverbeistä esitellään myös tyypit, joiden alkuosana on nominin taivutusmuoto (huoneeseenottaa, kivelheittää, avuksihuutaa, elooleikata, suutaantaa) ja substantiivin nominatiivimuoto (kiitosveisata). (S. 65-66.)

Tutkimus antaa uutta tietoa myös joidenkin Agricolan yhdyssanojen alkuperästä ja vakiintumisesta. Artikkeleissa tämä tarkastelu on melko vähäistä, ja yhteenvedossakin niistä kirjoitetaan vain muutaman sivun verran. Esitetyt tulokset ovat kuitenkin mielenkiintoisia.

Merkittävimpänä vierasta alkuperää olevana yhdyssanatyppinä pidetään adverbialkuisia yhdyssanoja (esim. läpitselukea, edesmennyt, kanssapalvelija), joiden malleiksi nimetään germaanisten ja klassisten kielten prefiksiverbit (s. 72). Tällaisia klassisen aineksen käännöksen sisältäviä yhdyssanoja olisi voinut tutkia tarkemminkin ja verrata niitä prefiksiverbien lisäksi niin sanottuihin uusklassisiin yhdyssanoihin, jollaisista ovat kirjoittaneet muun muassa Laurie Bauer (1998) ja Susan Olsen (2015). Myös Leena Koleh- mainen (2006: 3) on tehnyt eron uusklassisten yhdyssanojen ja prefiksiverbien välillä. Yhdyssanatyyppi lisääntyi runsaasti 180o-luvun tietokirjoissa, jolloin vieraiden kielten uusklassisten yhdyssanatermien pohjalta muodostettiin käännöslainoja. Esimerkiksi Elias Lönnrot muodosti latinan mallin mukaisesti kasvien rakenneoppiin termit toisparinen, vastosahainen ja vuoroparinen (esim. Pitkänen 2008: 109-110, 210-213). Laura Tyysterin (2015: 125, 128-130) mukaan nykysuomessa on yllättävän runsaasti yhdyssanoja, joiden alkuosana on jokin klassinen aines (esim. agri-, anti-, geo-, multi-).

Muodosteiden omaperäisyyttä on väitöskirjassa tarkasteltu vertailemalla yhdyssanoja lähdekielisiin vastineisiin. Jos Agricolalla toistuvalle muodosteelle ei ole voitu esittää käännöslainataustaa, sitä on arveltu omaperäiseksi. Omaperäisyyttä olisi voinut tarkastella nojautumalla myös vanhoihin murrenäytteisiin. Esimerkiksi Pernajan murteeseen vertailua ei ole tehty, vaikka yksittäisten omaperäisiksi arvioitujen sanojen (esim. luodenkannettu, ylenmielen) osalta murteissa esiintyminen olisi ollut helppo tarkistaa.

Väitöskirjan mukaan nykykieleen ovat säilyneet keskeisimmät ja jo keskiajalla tai varhain reformaatioaikana vakiintuneet yhdyssanat. Yhdyssanarakenteista yhdyssubstantiivit ovat olleet käytössä koko kirjakielen historian ajan (aviomies, elinaika, hiippakunta, opetuslapsi). Kuitenkin myös Agricolan käyttämät vierasperäiset yhdysverbirakenteet vakiintuivat jossain määrin. Esimerkiksi ristiinnaulita, vaarinottaa ja ylenkatsoa elävät yhä, ja tällaiset rakenteet ovat väitöskirjan mukaan myös jossain määrin produktiivisia (s. 74). Myös monet nykykielessä käytetyt yhdysadjektiivirakenteet ovat olleet jo Agricolalla käytössä (iankaikkinen, jokapäiväinen). Tarkastelluista rakenteista ylen-alkuisten yhdyssanojen joukko on nykykielessä selvästi suppeampi kuin Agricolalla, mutta sekin on yhä olemassa. Adjektiivialkuisten 
yhdyssubstantiivien alkuosan taipuminen kongruenssissa jälkiosan kanssa (esim. omaatuntoa, omassatunnossa) on nykyisin vähäisempää kuin Agricolalla, joskin vieläkin mahdollista.

Väitöskirja ei erityisesti uudista tai vahvista yhdyssanojen teoreettista kuvaamista, vaikka yksi tavoitteista oli yhdyssana-käsitteen arviointi vanhaa kirjakieltä edustavan aineiston pohjalta. Tutkimusaineisto olisi puutteineenkin mahdollistanut yleisemmän teorian tuottamisen niin yhdyssanoista kuin vanhasta kirjasuomesta. Ansiona voidaan kuitenkin pitää sitä, että tutkimus nostaa esiin myös kiinnostavia teoreettisia kysymyksiä, vaikka ei niihin tarkemmin paneudukaan.

Väitöskirja osoittaa, että yhdyssanatutkimus vanhan kirjasuomen teksteistä on tietyin rajoittein mahdollista. Se myös nostaa esiin tarpeen tutkia teoreettisemmin suomen kielen yhdyssanoja ja niiden kehitystä. Erikseen kirjoitettujen yhdyssanojen poimiminen aineistoon vaatisi semanttista arviointia, eikä käsin poimiminen näin laajasta aineistosta ole mahdollista. Tämän tyyppinen tutkimuskysymys nostaa esiin semanttisten hakukriteerien tarpeen automaattisissa hauissa.

Väitöskirjan päätelmissä todetaan, että Agricolan teoksissa sanayhtymien yhteen ja erikseen kirjoittaminen on "aiempaa luultua vakaampaa ja tarkoituksellisempaa" (s. 77). Tähän tulokseen täytyy kuitenkin suhtautua kriittisesti edellä esitettyjen aineistonkeruun puutteiden vuoksi. Päätelmään on tultu ennen kaikkea viimeisessä osatutkimuksessa (Toropainen 2016) arvioimalla niin sanottujen luontaisten yhdyssanojen erikseen kirjoitettujen esiintymien määrää. Lisäksi väitettä tukee ylen-alkuisia sanoja koskeva artikkeli (Toropainen 2014), jonka mukaan Agricola kirjoitti ylen-aineksen sisältävät yhtymät lähes poikkeuksetta yhteen. Erikseen kirjoitetut adjektiivialkuiset yhdyssubstantiivit ja genetiivialkuiset yhdyssanat - jos ne olisivat olleet mukana aineistossa - kuitenkin mahdollisesti horjuttaisivat käsitystä yhteen ja erilleen kirjoittamisen vakaudesta ja tarkoituksellisuudesta.

Viimeisin osatutkimus (Toropainen 2016) typografian vaikutuksesta yhteen ja erilleen kirjoittamiseen on erityisen kiinnostava ja näkökulmaltaan tuore. Siinä osoitetaan, että rivinvaihdon yhteydessä tuon ajan taittoteknisistä syistä yhdyssanoissa ei juuri käytetty tavuviivaa. Artikkeli nostaa esiin myös sen, että käytetyillä kapeilla palstoilla sananvälien pituudet vaihtelivat suuresti eikä aina ole senkään vuoksi selvää, mihin on alun perin tarkoitettu sananväli ja mihin ei.

Agricolan käyttämästä sanastosta, jota arvioidaan olevan 8500 eri lekseemiä (Jussila 1988: 207), yhdyssanoja on Toropaisen arvion mukaan vain 2500 eli noin $30 \%$. Nyky-yleiskielessä yhdyssanalekseemien osuus sanastosta on huomattavasti suurempi: esimerkiksi Nykysuomen sanakirjan hakusanoista yhdyssanoja on noin $65 \%$ (Saukkonen 1973). Jos vanhan kirjasuomen yhdyssanamäärät laskettaisiin semantiikka huomioiden, yhdyssanoja saattaisi kuitenkin olla selvästi enemmän. Joka tapauksessa niitä on Agricolan kielessä varmasti vähemmän kuin nykyisessä kirjakielessä.

\section{Agricolan yhdyssanat, osa I}

Toropaisen väitöskirjaa on syytä tarkastella osana aiempaa vanhan kirjasuomen tutkimusta sekä yhdyssanatutkimuksen kentässä. Agricolan kieltä on tutkittu 180o-luvulta alkaen. Kotuksen sanakirjatyön ohella sitä on viime aikoina tutkittu erityisesti Turun yliopistossa (esim. Häkkinen \& Vaittinen toim. 2007; Salmi 2011; Nummila 2012; Inaba 2015). Yhdyssanatutkimusta suomen kielestä on sen sijaan tehty melko vähän, ja leksikaalisessa morfologiassa on keskitytty johto-oppiin. Sanojen yhdistämistä on tietysti kuvattu jonkin verran kieliopeissa ja sananmuodostusta kuvaavissa tutkimuksissa, ja eri- 
tyisesti Iso suomen kielioppi (ISK 2004) on ottanut edeltäjiään paremmin yhdyssanat huomioon. Laajin Suomessa laadittu yhdyssanoja käsittelevä tutkimus on Laura Tyysterin (2015) väitöskirja, joka tarkastelee nykysuomen yhdyssanojen produktiivisuutta ja pohtii myös yhdyssanan käsitettä yksityiskohtaisemmin kuin aiemmat fennistiset tutkimukset.

Yhdyssanatutkimusta on kuitenkin tehty kansainvälisesti melko paljon. Muun muassa Bauer (esim. 1983, 2001) on tarkastellut sananmuodostuksen yhteydessä laajasti myös sanojen yhdistämistä. Lisäksi on tuoreita kokoomateoksia, joissa yhdyssanoja käsitellään laajasti, esimerkiksi Oxford handbook of compounding (Lieber \& Štekauer toim. 2011) ja Euroopan kielten sananmuodostusta tarkasteleva viisiosainen käsikirja Wordformation: An international handbook of the languages of Europe (Müller, Ohnheiser, Olsen \& Rainer toim. 2015-2016). Suomen kielestä tehdyn yhdyssanatutkimuksen toivoisi liittyvän vahvemmin tähän keskusteluun.

Toropaisen väitöskirja on hyvä jatko suomen kielestä tehdylle yhdyssanatutkimukselle ja hyvä alku vanhan kirjasuomen yhdyssanatutkimukselle. Agricolan yhdyssanoissa ja suomen kirjakielen varhaisissa yhdyssanoissa on paljon kiinnostavaa, eikä tämä väitöskirja anna vielä tyhjentäviä vastauksia. Kuten tekijä itsekin toteaa (s. 32), "[v]aihtelusta huolimatta vanhan kirjasuomen yhdyssanoja voi mielestäni tutkia, ja tutkimuksessa kannattaa lähteä liikkeelle yhteen kirjoitetuista yhtymistä, joita esimerkiksi Agricolan teoksissa on tuhansia”. Tämä on hyvä lähtökohta, ja toivon yleisesti yhdyssanatutkimuksen kannalta, että suomen kielen yhdyssanojen vakiintumista ja yhteen kirjoittamisen normia tarkasteltaisiin jatkossa vielä siten, että otettaisiin huomioon nekin vanhan kirjasuomen yhdyssanat, jotka kirjoitettiin erikseen.

\section{KaArina Pitkänen-Heikkilä} etunimi.pitkanen@helsinki.fi

Kirjoittaja on suomen kielen yliopistonlehtori Helsingin yliopistossa. Hän toimi Toropaisen vastaväittäjänä.

\section{Lähteet}

BAUer, LAUrie 1983: English wordformation. Cambridge: Cambridge University Press.

_ 1998: Is there a class of neoclassical compounds in English and is it productive? - Linguistics 36 s. 403-422.

- 2001: Morphological productivity. Cambridge: Cambridge University Press.

Häkminen, Kaisa - Vaittinen, Tanja (toim.) 2007: Agricolan aika. Helsinki: BTJ Finland Oy.

InABA, Nobufumi 2015: Suomen datiivigenetiivin juuret vertailevan menetelmän valossa. Suomalais-Ugrilaisen Seuran Toimituksia 272. Helsinki: SuomalaisUgrilainen Seura.

ISK = HAKULINEN, AUli - Vilkuna, Maria - Korhonen, Rittta Koivisto, Vesa - Heinonen, Tarja RiIt ta - Alho, IrJa 2004: Iso suomen kielioppi. Helsinki: Suomalaisen Kirjallisuuden Seura.

Jussila, Raimo 1988: Agricolan sanasto ja nykysuomi. - Esko Koivusalo (toim.), Mikael Agricolan kieli s. 203-228. Tietolipas 112. Helsinki: Suomalaisen Kirjallisuuden Seura.

KoIVisto, Vesa 2013: Suomen sanojen rakenne. Helsinki: Suomalaisen Kirjallisuuden Seura.

Kolehmainen, Leena 2006: Saksan ja suomen verbien morfologiaa, fraseologiaa, semantiikkaa ja valenssinmuutoksia. - Virittäjä 110. http://www.kotikielenseura.fi/virittaja/hakemistot/jutut/ kolehmainen2_2006.pdf (10.12.2017).

LAIne, PäIVI 2007: Suomi tiellä sivistyskieleksi. Suomenkielisen maantieteen 
sanaston kehittyminen ja kehittäminen 180o-luvulla. Turun yliopiston suomalaisen ja yleisen kielitieteen laitoksen julkaisuja 77. Turku: Turun yliopisto.

Lieber, Rochelle - Štekauer, Pavol (toim.) 2011: The Oxford handbook of compounding. Oxford University Press: Oxford. https://doi.org/10.1093/oxfordhb/9780199695720.001.0001.

Müller, Peter O. - Ohnheiser, IngeBorg - Olsen, SusAn - RAINER, FrANZ (toim.) 2015-2016: Wordformation. An international handbook of the languages of Europe. I-V. Berlin: De Gruyter Mouton.

Nummila, Kirsi-Maria 2012: Tekijännimet Mikael Agricolan teosten kielessä. Henkilötarkoitteisten johdosten merkitykset, funktiot ja rakenteet. Annales Universitatis Turkuensis C 328. Turku: Turun yliopisto.

Olsen, Susan 2015: Composition. - Peter O. Müller, Ingeborg Ohnheiser, Susan Olsen \& Franz Rainer (toim.), Wordformation. An international handbook of the languages of Europe s. 364-386. Berlin: De Gruyter Mouton.

Pitkänen, KaArina 2008: Suomi kasvitieteen kieleksi. Elias Lönnrot termistön kehittäjänä. Suomalaisen Kirjallisuuden Seuran Tutkimuksia 1164. Helsinki: Suomalaisen Kirjallisuuden Seura.
SAlmi, Heidi 2011: Mikael Agricolan teosten ala-, ylä- ja pää-vartaloiset adpositiot. Annales Universitatis Turkuensis C 307. Turku: Turun yliopisto.

Saukkonen, Pauli 1973: Suomen kielen yhdyssanojen rakenne. - Commentationes Fenno-Ugricae in honorem Erkki Itkonen s. 332-339. Suomalais-Ugrilaisen Seuran Toimituksia 150. Helsinki: Suomalais-Ugrilainen Seura.

Tieteen termipankki. http://www.tieteentermipankki.fi.

Toropainen, TANjA 2014: Ylen-alkuiset sanat Mikael Agricolan teoksissa. - Sananjalka 56 s. 29-49.

_ 2015: Adjektiivialkuiset yhdyssubstantiivit Mikael Agricolan teoksissa. - Sananjalka 57 s. 54-85.

_ 2016: Typografian vaikutus yhdyssubstantiivien oikeinkirjoitukseen Agricolan teoksissa. - Sananjalka 58 s. 175-198.

Tyysteri, Laura 2015: Aamiaiskahvilasta ötökkätarjontaan. Suomen kirjoitetun yleiskielen morfosyntaktisten yhdyssanarakenteiden produktiivisuus. Turun yliopiston julkaisuja C: 408. Turku: Turun yliopisto.

VAittinen, TANJA 2003: Vanhan kirjasuomen yhdysverbit. - Sananjalka 45 s. $118-133$.

2007: Mikael Agricolan teosten yhdysadjektiivit. - Virittäjä 111 s. 523-542.

\section{Tuoretta tietoa Suomessa puhuttavasta karjalan kielestä}

Anneli Sarhimaa: Vaietut ja vaiennetut. Karjalankieliset karjalaiset Suomessa. Tietolipas 256. Helsinki: Suomalaisen Kirjallisuuden Seura 2017. 297 s. ISBN 978-952-222-890-1.
Anneli Sarhimaa on julkaissut laajan monografian Suomessa puhuttavasta karjalan kielestä, sen nykytilasta, historiasta sekä karjalaisesta kulttuurista. Teos perustuu tutkimushanke ELDIAn (Euro- 